\title{
Contemporary Inheritance and Changes of Marriage Culture of the Yao Nationality in N Village, $F$ Town, Zhaoping County, Hezhou City
}

\author{
Dan Chen \\ Institute of Nanling National Corridor, Hezhou University, Hezhou, 542899, China
}

Keywords: The Yao nationality, Marriage, Inheritance, Changes.

\begin{abstract}
After an investigation and research on the contemporary inheritance and changes of marriage culture of the Yao nationality in N village, F town, Zhaoping County, Hezhou City from the perspective of love way, engagement and marriage form, distance between both sexes, divorce, etc, we think the marriage of the Yao nationality in this village has been changed in many forms, but the values such as the equality of men and women and the wills of parties and ancestor worship have not been changed substantively. Thus it shows the core value and religion of a nationality is the soul of marriage culture.
\end{abstract}

\section{Introduction}

Hezhou City in Guangxi Zhuang Autonomous Region is an important concentrated area of the Yao nationality in China, and it also the confluence of the famous Central Plain Culture and Lingnan Culture. The Yao nationality in Hezhou City has a long history and numerous branches. The social environment and the means of livelihood of every branch and the ethical ideas and cultural memory that they bear differ from each other in thousands of ways, and these differences interact with their marriage to form the unique marriage culture. With the development of social economy and the expansion of foreign contacts, the marriage of the Yao nationality is changing constantly in the interaction between tradition and modernity. To understand the contemporary changes of the marriage culture in this ethnic group is of great value for us to know its marriage and family structure, ethical norms and the future development trend of the value orientation.

\section{General situation of $\mathbf{N}$ Village}

N Village is located at the juncture of Zhaoping County and Pinggui District of Hezhou City and Cangwu County of Wuzhou City, which is $82 \mathrm{~km}$ north of Hezhou City and $71 \mathrm{~km}$ south of Wuzhou City, and which is one of the two Yao villages in F Town, Zhaoping County, Hezhou City and one of the traditional Guoshan Yao (an important branch of the Yao nationality) villages with the largest population. $\mathrm{N}$ Village has a typical mountain terrain and the villagers are scattered relatively. At present, there are 168 households and 698 persons in whole village with six surnames: Deng, Zhao, Feng, Huang, Li, Chen and Zheng, distributed in 5 natural villages. The genealogy of Deng in this village shows that $\mathrm{N}$ Village was built during the reign of Emperor Qianlong of Qing Dynasty and has lasted for more than 220 years. The total cultivated area in N Village is $210 \mathrm{mu}$ and the per capita cultivated area is about $0.3 \mathrm{mu}$, so agricultural economy base is weak but its forest coverage rate is above $85 \%$. Therefore, the traditional means of livelihood of the Yao nationality in $\mathrm{N}$ Village is mainly half-ploughing and half-hunting with forest economy as supplement. After the reform and opening-up, the state began to popularize the planting of China firs, so now the wood business has become the main finance source for most families. 


\section{Investigation of the current marriage situation of the Guoshan Yao in N Village}

\section{Inheritance of traditional marriage custom}

Son-in-law by adoption is still popular.

Son-in-law by adoption is a marriage form that a man gets married a woman in the woman's family and becomes a member of the wife's family. The son-in-law by adoption is often discriminated by the society in many nationalities and regions of China, and the fate of the sons-in-law living in their wives' families usually is tragic. However, the Yao nationality pays attention to the equality of men and women, and the son-in-law by adoption without any discrimination is the biggest national feature in the marriage culture of the Yao nationality. However, a family has a daughter but no son will ask a son-in-law by adoption, and a family has both daughter and son will ask a daughter-in-law by adoption and marry a daughter to the other family in most cases. However, if the family loves the daughter more the son, it will send the son to the other family as a son-in-law by adoption and require another son-in-law by adoption. At present, the son-in-law by adoption is still one of popular marriage forms for the Yao nationality in N Village.

\section{Free communication before marriage and popular trial marriage}

The Yao nationality in $\mathrm{N}$ Village always has the tradition of free communication and trial marriage before marriage. Trial marriage means test marriage as its name implies, which is not official, but a test before the official marriage. In N Village, a man and a woman will take half a year to confirm the love relationship and then enter into the stage of trial marriage after their parents are introduced by the matchmaker. The duration of trial marriage is half a year, during which, the man and woman will have dinner together, live together and work together and can have sex with each other. If both parties get along with each other after about half a year of trial marriage, they can get married. If one party thinks they don't get along with each other, they can break up peacefully and the other party shall not intervene. Even if the woman is pregnant during the period of trial marriage, it cannot be the reason for getting married, and she only selects induced abortion. After breaking up, both parties can seek a new love object without any discrimination, and they will not be even doubted as a wanton or a person always chopping and changing. This custom has been inherited to now.

"Discussion with the parents of the daughter-in-law or son-in-law" is still the core of marriage system.

"Discussion with the parents of the daughter-in-law or son-in-law" is the core link in the marriage of the Yao nationality in N Village, which means the parents of both man and woman sit down to discuss the marriage affairs at the appointed time under the witness of the "matchmaker" (who is temporary in most cases): whether agree the marriage, son-in-law by adoption of daughter-in-low by adoption, how to hold the wedding and others. When talking to each other, they must speak all related things clearly and reach a consensus, or else they shall not hold the wedding. And the affairs agreed shall not be changed. It is introduced that there were two cases in recent years that both parties broke up because their parents didn't reach a consensus during the link of Discussion. In most cases, the parents of both parties are considerate of each other, and there are few cases without a consensus. Even if the parents of both parties are divided while discussing, the marriage is decided by the man and woman. The society will not have any criticism of both parties.

The process to marry a bride and a son-in-law by adoption is same.

The process to marry a bride in the Yao nationality in $\mathrm{N}$ Village is very simple without too many unnecessary and over-elaborated formalities. Especially when both parties are the Yao nationality, they only agree the wedding time while Discussing, and then the bride will leave for the groom's house on time with escort the relatives and friends, and the groom doesn't need to go to the bride's house to escort her back to the wedding. The team of escort usually contains 3 relatives and friends and 1 matchmaker. If one party is from other nationality, the wedding process can be changed flexibly according to reality to respect the custom of the other party. Son-in-law by adoption is also called to marry a "male daughter-in-low", and the process is same with that of marrying a daughter-in-low. After marriage, when the labor force in both parties' families is not enough, they shall help both families traditionally, namely, they shall give consideration to both families. However, when the 
distance between the families of both parties is too far and they are possible to give consideration to both families, they will exchange labor with neighbors at ordinary times so as to be helped by the neighbors in busy season.

The custom of worshiping the "family ancestor" in the wedding is still reserved.

The Yao nationality adores the ancestors very much. Ancestor worship means they believe the souls of their ancestors are not disappeared and become a part of supernature. Ancestor worship has been popular for a long tome in China and influenced all aspects of the society deeply and lastingly. The wedding is the most important etiquette in people's life and a great event in a family, so the Yao nationality in $\mathrm{N}$ Village will invite a master (a religious clergy) to host the ceremony for the new couple and invite the parting ancestors to go home to participate in and witness the great happy event and bless the new couple. The rich families will worship the "family ancestor" and drive out evil spirits at night for three days to guarantee the couple are happy after marriage and their descendants are prosperous and flourishing. At present, although the wedding ceremony of the Yao nationality in N Village has been Hanized deeply, the link of worshiping the "family ancestor" in the wedding is not omitted.

The wedding is simplified without discrimination

To hold a simple wedding or a grand weeding in the Yao nationality of N Village is decided by the family economic conditions of the parties. It they are real poor, they can select not to hold a wedding and will not be criticized. However, generally, they will invite their close relatives, such as aunts and uncles to form one or two tables of banquet. At present, with the development of social economy, the economic conditions of most families have been improved obviously and most young people have seen the world, so the situation without wedding is less. If it is a remarriage, the wedding is very simple relatively.

The custom of "Liangtouding" is still popular.

In the Yao nationality of $\mathrm{N}$ Village, "Liangtouding" means the surname selection for the son-in-law's children shall meet both parties' wills to the greatest extent. If the first child is surnamed with the maternal surname, the second child shall be surnamed with the paternal surname, and so on. For the son-in-law by adoption, the wife's family needs a son to inherit the "shrine" passed on from generation to generation, so to have a son is significant, or else the son-in-law cannot obtain the "ancestral land". Therefore, many couples will have more children as soon as possible as long as they can. Due to the under-population of the Yao nationality in Hezhou, the local Yao people are connived to have more children outside the state plan even though the one-child policy was implemented strictly started from 1980s, which guarantees the reservation of the custom of "Liangtouding".

\section{Changes of traditional marriage custom}

The form of singing folk songs declines and the love means are more flexible and varied.

The Yao nationality is good at singing and dancing. Both Yao men and women in N Village like singing traditional Yao folk songs. Singing folk songs is a traditional love hotbed for Yao youth. With the acceleration of social development and the popularization of televisions, computers and cellphones, the traditional custom of singing folk songs is gradually disappearing, and there are few people in the young generation who can sing Yao songs, so the forms of "making friends by singing songs" and "playing matchmakers by singing songs" are becoming a remote historical memory. In the past, there was a window in every adult girl's boudoir in $\mathrm{N}$ Village. Once a man and woman understood each other and fell in love and as long as the woman didn't refuse, the man could go to knock on the window and entered into woman's boudoir at night, which is commonly known as "climbing the window". However, this love custom has disappeared. At present, cellphone, QQ, WeChat have become the main media for men and women to fall in love with each other. It is very rare to know each other by the introduction of peers or by special matchmakers.

The divorce rate rises.

In the past, the Yao people devoiced rarely. However, in recent years, the divorce rate has risen. According to the analysis of the director of the village committee, the main reason for the rise in divorce rate is that many people went out to work to result in long-term separation of husbands and 
wives. Among them, the cases that women were unable to bear the outside colorful world and tempted by others when they went out to work for long term were in the majority. However, among the people living locally for long time, the divorce cases were rare, which was mainly due to their religion. For example, Mr. Deng living in N Village as a son-in-law by adoption divorced his wife about ten years ago, the reason was that he thought the Five Elements (metal, wood, water, fire and earth) of his wife conflicted with that of his, and he would die soon if he didn't divorce. After he filed for divorce, the court affirmed that he was adamant and the mutual affection had broken down, and then sentenced him to divorce.

The intermarriage scope is expanded and many women marry the men from other nationalities.

In the past, most women in the Yao branches didn't marry out, but they didn't refuse the other nationalities or the men from other villages to be son-in-law by adoption. The main reason was that they were worried about that if a large number of women married out, it would cause the ratio imbalance of male and female of the nationality and endanger the national reproduction and survival. Therefore, in the traditional society of Yao nationality, if a woman married out, she would be punished severely. Before the democratic reform, the livelihood of the Yao nationality in N Village was hard and hardly any woman from other nationality married into N Village. Most men from other nationalities as son-in-law by adoption in N Village were the businessmen engaged in wood business in this place. Since the establishment of new China, the intermarriage scope of the Yao nationality in N Village has not been limited to the surrounding counties (districts). Especially since 1990s, with the improvement of traffic conditions, many Yao children in N Village have gone out to work, so that the intermarriage scope has been further expanded. In the information provided by the village committee, the women married into N Village come from Henan and Hubei farthest, and near Hunan, Jiangxi and Guangdong. All these women marrying into $\mathrm{N}$ Village knew their husbands when they worked outside. At present, there are more than 30 women from other provinces marrying into N Village, and all of them were taken back by the men in N Village when they worked in Guangzhou, Foshan and other places. In addition, more and more Yao women in N Village married out when they worked out. A village cadre introduced that some local girls are unwilling to marry local Yao men and they think they will stay for a lifetime in the mountain area without future, so most of them hope to marry out. However, in terms of quantity, the number of women from other provinces marrying local Yao men is larger than that marrying out.

The influence of economic factors is increasing.

Marriage is a superstructure, which is certainly restricted by the economic base. The economic condition is gradually becoming a factor influencing the marriage culture of the Yao nationality in $\mathrm{N}$ Village. One aspect of this influence shows that the economic condition has gradually become one of the standards of choosing spouse. In recent years, some isolated cases appeared in the village that some women's parents worried about their daughters' suffering and refused to agree them to marry the men with poor economic conditions. Some girls also admitted that economic condition is one of the standards of choosing spouse. For the men and women remarrying, the economic condition has especially become the key to the success of marriage. On the other hand, that whether the wedding ceremony is held simply or grandly is not criticized by the society. But the wedding scale is related to the honor of the village. The director of $\mathrm{N}$ Village Committee introduced that the case appeared that some villagers in different villages of $\mathrm{F}$ Town flaunted wealth in weddings privately. According to local prices, the cost of holding a wedding is about RMB20000 to 30000, and this figure is huge for all people in F Town. For this purpose, some villages make an unwritten rule for the whip-round for the weddings of the villagers. In other words, at least one people of a household (taking the household as the unit in the village) shall participate in the wedding held by the villager in this village, and the whip-round of every household shall not be less than RMB108 or 109. This can not only help the party financially, but also manifest the economic strength and generosity of villagers in this village, so usually the family holding the wedding doesn't loose money.

The phenomenon of early marriage disappears.

Before the democratic reform, the phenomenon of early marriage in the Yao nationality of $\mathrm{N}$ Village prevailed, and both men and women usually married at 16 years old. At present, the 
phenomenon of trial marriage still exists, but after the establishment of new China, the Marriage Law has been popularized in the Yao area, which has been responded positively by many people. The phenomenon of early marriage has disappeared and the Yao youth in $\mathrm{N}$ Village get married at the legally marriageable age. The practice that people must fulfill the legal marriage process has permeated through the people, and up to now, very few people fail to fulfill the marriage law and don't get the marriage license.

In addition to the above mentioned, there are some obvious changes. For example, with the improvement of the villagers' economic conditions, the structure of "twelve bowls" on the wedding banquet is not changed, but the grade of dishes has been improved greatly. In the past weddings, a "song hall" was formed naturally and people sang songs for continuous three days and nights, but now all people spend money to invite special "master" to sing. The range of the appearance fee for the "master" is from RMB300 to 400. Bridesmaids also appear in weddings, etc.

\section{Conclusion}

As a superstructure, marriage is the concentrated reflection of the social economy, historic culture, religion and ethics of an ethnic group. In the forward development process of social economy, there are many factors influencing the inheritance and changes of marriage culture, but ethics and religion are always are the core. Although the marriage of the Yao nationality in N Village has been changed greatly, its core values, such as the equality of men and women, the wills of parties and ancestor worship are not changed substantively, which is the key to understand the law of the inheritance and changes of the Yao nationality in N Village, and also is the enlightenment to research the inheritance and changes of the marriage culture of the Yao nationality in $\mathrm{N}$ Village.

\section{References}

[1] Dictionary of Chinese Kinship, chiefly edited by Liu Chaoban, Wuhan Publishing House, 1991(8),pp.158.

[2] Introduction to Anthropology, chiefly edited by Zhou Daming, Sun Yat-Sen University Press, 2016 (7), pp.168.

[3] Introduction to Chinese Culture (the 3rd Edition), chiefly edited by Chen Jiangfeng, Nanjing: Nanjing University Press, 2014, 145. 